\title{
THE EFFECT OF REPRESSING ON SURFACE TOPOGRAPHY AND MICROSHEAR BOND STRENGTH OF TWO PRESSABLE CERAMICS
}

\author{
Zeinab N. Emam*
}

\begin{abstract}
Statement of the problem: Pressable ceramic materials are available in ingots with different sizes. Large ingots can be completely or partly utilized, consequently a significant amount of leftover materials are frequently thrown away by laboratory technicians. Accordingly reuse of this leftovers might affect the microstructure which could affect the material properties such as mechanical properties as well as surface topography and micro-shear bond strength.

Objective: This in-vitro study was carried out to investigate the effect of repressing on surface topography and micro-shear bond strength of Lithium di-silicate (IPS e.max press) and zirconia reinforced lithium di-silicate (Celtra press).

Materials and Methods: Two commercially available glass ceramic materials were used in this study; IPS e.max press (Ivoclar, vivadent) and Celtra press (Dentsply, Sirona). The two materials were used to fabricate disc samples. A total of thirty two ceramic disc specimens with $1.2 \mathrm{~mm}$ height and $12 \mathrm{~mm}$ diameter were constructed. The flat round disc samples for each material $(\mathrm{n}=16)$ were randomly divided into two equal groups: group I: Pressed ceramic discs and group II: Repressed ceramic discs $(n=8)$. The disc samples were further subdivided into two equal subgroups according to the type of cement used $(n=4)$ : subgroup A: samples were cemented with Multilink automixed ,self-adhesive resin cement. Subgroup B: samples were cemented with Rely X-unicem 2 automixed, self-adhesive resin cement. Fabrication of disc samples for the two tested materials, surface treatment and cementation procedures were done for both types of cements according to manufacturer instructions. Surface topography and microshear bond strength were assessed using a universal testing machine. The mode of failure of the debonded specimens was verified by SEM. The resulted data were gathered, organized in tables and statistically analyzed.
\end{abstract}

Results: For IPS e.max or Celtra press; there was no statistically significant difference between mean Ra value $(\mu \mathrm{m})$ of press and repress conditions. IPS e.max showed statistically significantly higher mean micro-shear bond strength than Celtra press. Regardless of ceramic material and condition (press, repress); there was no statistically significant difference between mean microshear bond strength of the two cements used. Apart from ceramic material and cement type; press group showed statistically significant higher mean micro-shear bond strength than repress group.

Conclusions: Pressing of glass ceramics for one injection is recommended. Repressing of glass ceramics improved surface topography but compromises the bond strength. Both tested glass ceramic materials can be recycled without significantly altering the surface roughness.

Keyword: Repressing, Surface topography, Microshear bond strength, Pressable ceramics, Celtra press, IPS e.max press.

* Associate Professor, Fixed Prosthodontics Department, Faculty of Dentistry, Cairo University, Egypt, Associate Professor, Fixed Prosthodontics Division, Oral and Maxillofacial Department, Faculty of Dentistry, Umm Al - Qura university, KSA. 


\section{INTRODUCTION}

Glass ceramics can be manufactured by various laboratory techniques, such as brush (layering) technique, heat pressing and $\mathrm{CAD} / \mathrm{CAM}$ system due to the increased clinical success rate of these systems. ${ }^{1}$ Pressing technology displayed particular advantages as compared to other techniques such as less porosities and better marginal fit. ${ }^{2,3,4}$ Wax pattern is needed for utilizing this technique, surrounded by a particular investment as recommended by the manufacturer ,placed in an oven aiming for wax evaporation, subsequently the mould cavity is filled under vacuum then heat pressed with ceramic ingots. Leucite based and lithium di-silicate based glass ceramic are introduced in different color shade in order to mimic and satisfy the clinical needs. ${ }^{5}$

The persistent demand for obtaining all ceramic restoration that merges between excellent esthetics and optimum mechanical properties has participated to the elaboration of reinforced glass ceramics, for example zirconia reinforced glass ceramics (Celtra Duo, Celtra Press), manufactured by CAD/CAM system and Pressing technology respectively and both introduced to dental field by (Dentsly ; Sirona).

A strong bond between the glass ceramic restoration and underlying tooth structure offers good support for the restoration; Moreover the functional stresses to tooth/restoration interfaces were uniformly transmitted arising the clinical success rate. ${ }^{6,7}$ For glass ceramic restorations, in order to obtain an effective bonding, the glassy matrix is chemically treated by $5 \%$ hydrofluoric acid etching in order to obtain a rougher surface to perform micromechanical interlocking with adhesive resin cement. ${ }^{89}$ According to manufacturer recommendation of lithium di-silicate based ceramics, using $4.8 \%$ hydrofluoric acid for 20 seconds is advisable, ${ }^{10}$ then silane coupling agent was applied to the etched ceramic surface to act as a bi-functional molecule with inorganic segment to bond with ceramic surface and organic segment to bond with adhesive resin cement. ${ }^{11,12}$ Following hydrofluoric acid etching and silanization, wettability will be increased resulting in decreased contact angle and enhanced bond strength. ${ }^{10}$

The selection of resin based cements is recommended by dentists as a result of their lowered solubility in oral fluids as well as reduce incidence of microleakage ,so decreasing the chance for recurrent decay.${ }^{13}$ Self-adhesive resin cements signifies the highly simplified category of resin based cements, so expanding popularity in cementing the majority of all ceramic restorations due to the ease of use, no pre-modifications required to hard tooth structures either etching or adhesive bonding. ${ }^{14}$

Effectiveness of bond might affect the long span clinical success of all ceramic restorations. Several tests are used for measuring bond strength such as macro and micro bond strength for example; tensile, shear, micro-tensile and micro-shear bond strength tests. ${ }^{15}$ One of the benefits of micro-shear bond strength test is that, it doesn't necessitate any trimming of the specimen, the bonding surface is intact, and stress distribution is uniform as an ultrasmall area of bonding interface is tested. Therefore, it produces safer and more accurate assessment of the bonding interface; however, the testing procedures are very technique sensitive..$^{10}$

Surface topography, degree of smoothness of all ceramic restorations is an essential property warranting an optimum esthetic quality and a secured long term clinical success rate. ${ }^{16,17}$ Unsatisfactory finished all ceramic restoration surfaces might cause increased tendency to discoloration, plaque deposits, wear to opposing restoration or hard dental structures, decreased translucency as well as decreased mechanical properties leading to subsequent failure of the restoration. The surface roughness of all ceramic restorative materials is influenced by discrete aspects and conditions. ${ }^{18,19} \mathrm{~A}$ clinically satisfactory $\mathrm{Ra}$ threshold for restorative material was stated to be $0.2 \mu \mathrm{m}$ and excessive plaque formation occur when $\mathrm{Ra}>0.2 \mu \mathrm{m} .^{20}$ 
Pressable ceramic materials are available in ingots with pre-adjusted dimensions and sizes. Small ingots that weigh 3.2 grams and large ingots that weigh 6.1 grams. Large sized ingots are used to press multiple restorations in same time, so glass ceramic ingots can be completely or partly utilized, consequently a significant amount of waste material is frequently thrown away by laboratory technicians. ${ }^{21}$ Ideally the buttons and sprues should not be reused, although it has been stated that some dental laboratories reused the remnants from pressing procedures like sprues and buttons for repressing new restorations. Little information is available regarding the effect of repressing on surface topography as well as the bond strength of lithium di silicate and zirconia reinforced lithium di-silicate glass ceramics, as repressing may change the material microstructure, thus might affect the surface topography and adhesive properties of both materials. 22,23,24,25 Literature does not provide any detailed information of whether repressing of the remaining glass ceramic materials might alter the material adhesive characteristics as well as material surface topography. A few studies have reported that repressing has unfavorable effect on density, porosity, surface hardness and flexural strength of lithium di-silicate glass ceramics..$^{21,26}$

Therefore, further investigation is required to assess the effect of heat repressing on surface topography and micro-shear bond strength for IPS e.max and Celtra press. Thus the null hypotheses were that IPS emax press and Celtra press repressing has no adverse effect on (1) Surface topography (2) Micro-shear bond strength.

\section{MATERIALS AND METHODS}

Two commercially available glass ceramic materials were used in this study; IPS e.max press (Ivoclar, vivadent) and Celtra press (Dentsply, Sirona). The two materials were used to fabricate disc samples. A total of thirty two ceramic disc specimens with $1.2 \mathrm{~mm}$ height and $12 \mathrm{~mm}$ diameter were constructed; The flat round disc samples for each material were randomly divided into two equal groups: group I: Pressed ceramic discs and group II: Repressed ceramic discs ( $\mathrm{n}=8)$. The disc samples were further subdivided into two equal subgroups according to the type of cement used $(n=4)$ : Subgroup A: samples were cemented with Multilink; bis GMA based self-adhesive, auto-mixed dual cured resin cement. Subgroup B: samples were cemented with Rely -X unicem 2; phosphate monomer based self-adhesive, auto-mixed dual cured resin cement. Sample grouping was shown in Table (1).

\section{Fabrication of the ceramic discs}

For the purpose of construction of a standardized disc shaped wax pattern, a split custom made Teflon mold was fabricated with $12 \mathrm{~mm}$ diameter and 1.2 mm height. Disc shaped wax patterns were sprued and invested in IPS Press Vest investment material (Ivoclar-Vivadent) for pressed group (group I). After pressing, divesting was done following the manufacturer's instructions. Then sprues and buttons were splitted from the pressed disc samples using a fine diamond disc (940-Brasseler-Ga), then filing and fine modifications were done in order to facilitate proper insertion in the investment moulds for repressing (group II). The same steps were performed for construction of the repressed group as spruing, investing, wax burn out, pressing and divesting .Disc samples were examined for any defects, finishing and polishing was performed on the veneer side for both groups, and then placed in ultrasonic bath for 10 minutes and air dried for debris removal matching with manufacturer instructions. The chemical composition of the materials used in this study is presented in Table (2).

\section{Surface Topography evaluation}

Quantitative characterization of surface topography (Ra values in $\mu \mathrm{m}$ ) was carried out using an optical method. Specimens were photographed using USB Digital microscope with a built-in camera (Scope Digital Microscope- Guangdong/ China) at a fixed magnification. The images were 
TABLE (1) Sample Grouping.

\begin{tabular}{|c|c|c|c|c|c|c|c|c|}
\hline \multirow{2}{*}{$\begin{array}{c}\text { Glass } \\
\text { ceramic } \\
\text { materials } \\
\text { used }\end{array}$} & \multicolumn{4}{|c|}{ IPS e.max Press } & \multicolumn{4}{c|}{ Celtra Press } \\
\cline { 2 - 8 } & \multicolumn{2}{|c|}{$\begin{array}{c}\text { Group I } \\
\text { (Press group) }\end{array}$} & \multicolumn{2}{|c|}{$\begin{array}{c}\text { Group II } \\
\text { (Repress group) }\end{array}$} & \multicolumn{2}{c|}{$\begin{array}{c}\text { Group I } \\
\text { (Press group) }\end{array}$} & \multicolumn{2}{c|}{$\begin{array}{c}\text { Group II } \\
\text { (Repress group) }\end{array}$} \\
\hline $\begin{array}{c}\text { Adhesive } \\
\text { resin }\end{array}$ & $\begin{array}{c}\text { Subgroup } \\
\text { (A) }\end{array}$ & $\begin{array}{c}\text { Subgroup } \\
\text { (B) }\end{array}$ & $\begin{array}{c}\text { Subgroup } \\
\text { (A) }\end{array}$ & $\begin{array}{c}\text { Subgroup } \\
\text { (B) }\end{array}$ & $\begin{array}{c}\text { Subgroup } \\
\text { (A) }\end{array}$ & $\begin{array}{c}\text { Subgroup } \\
\text { (B) }\end{array}$ & $\begin{array}{c}\text { Subgroup } \\
\text { (A) }\end{array}$ & $\begin{array}{c}\text { Subgroup } \\
\text { (B) }\end{array}$ \\
used & $\begin{array}{c}\text { Multilink } \\
\text { automix }\end{array}$ & $\begin{array}{c}\text { Rely-X } \\
\text { unicem2 } \\
\text { automix }\end{array}$ & $\begin{array}{c}\text { Multilink } \\
\text { automix }\end{array}$ & $\begin{array}{c}\text { Rely-X } \\
\text { unicem2 } \\
\text { automix }\end{array}$ & $\begin{array}{c}\text { Multilink } \\
\text { automix }\end{array}$ & $\begin{array}{c}\text { Rely-X } \\
\text { unicem2 } \\
\text { automix }\end{array}$ & $\begin{array}{c}\text { Multilink } \\
\text { automix }\end{array}$ & $\begin{array}{c}\text { Rely-X } \\
\text { unicem2 } \\
\text { automix }\end{array}$ \\
\hline
\end{tabular}

TABLE (2) The chemical composition of the materials used in this study.

\begin{tabular}{|l|l|l|}
\hline Material & Composition & Manufacturer \\
\hline IPS e-max Press & $\mathrm{SiO}$ / Li2O/ P2O5/ K2O/ ZrO2/ other oxides and ceramic pigments & Ivoclar-Vivadent \\
\hline Celtra Press & $\begin{array}{l}\mathrm{SiO} 2 / \mathrm{Li} 2 \mathrm{O} / \mathrm{P} 2 \mathrm{O} 5 / \mathrm{ZrO} 2 / \mathrm{Al2O} / \mathrm{K} 2 \mathrm{O} / \mathrm{CeO} \text { and other oxides and } \\
\text { pigments. }\end{array}$ & $\begin{array}{l}\text { Dentsply-Konstanz- } \\
\text { Germany. }\end{array}$ \\
\hline $\begin{array}{l}\text { Multilink } \\
\text { Automix resin cement }\end{array}$ & $\begin{array}{l}\text { Dimethacrylates ; HEMA; ytterbium trifluoride; Silica; } \\
\text { catalyst;stabilizers; ;ibenzoyl peroxide ; pigments. }\end{array}$ & Ivoclar-Vivadent \\
\hline $\begin{array}{l}\text { Rely X- unicem automix } \\
\text { resin cement }\end{array}$ & $\begin{array}{l}\text { Methacrylate monomers containing phosphoric acid groups /Methacrylate } \\
\text { monomers /Initiator component and Stabilizers/Alkaline (basic) fillers / } \\
\text { Silanated fillers /Initiator components and Pigments and rheological } \\
\text { additives }\end{array}$ & $\begin{array}{l}\text { 3M ESPE- } \\
\text { Germany. }\end{array}$ \\
\hline
\end{tabular}

recorded with a resolution of $1280 \times 1024$ pixels per image. Digital microscope images were cropped to $350 \times 400$ pixels using Microsoft office picture manager to specify area of roughness measurement. Within the software, all limits, sizes, frames and measured parameters are expressed in pixels.

System adjustment was done to translate the pixels into measuring units. . Subsequently, a 3D image of the surface profile of the specimens was created. Three 3D images were collected for each specimen, both in the center of the discs and in the sides at area of $10 \mu \mathrm{m} \times 10 \mu \mathrm{m}$. This software was used to calculate the average surface roughness values ( $\mathrm{Ra}$ ) expressed in $\mu \mathrm{m}$ of the average height of each specimen. ${ }^{27}$

\section{Cementation procedures}

Following manufacturer recommendations, surface treatment was done for one side of each ceramic disc (The fitting surface of the restoration) using $5 \%$ hydrofluoric acid gel (IPS Ceramic etching gel; Ivoclar ;Vivadent) for 20 seconds for IPS e.max press and 30 seconds for Celtra press. Rinsed with air water spray for 30 was done, followed by washing using distilled water and air drying. Afterwards silane coupling agent (Mono bond plus; Ivoclar; Vivadent ) was smeared in a thin coat and left to react and evaporate for $60 \mathrm{~s}$. Small transparent microtubules were cut from polyvinyl tube with internal diameter of $0.9 \mathrm{~mm}$ and a height of $0.5 \mathrm{~mm}$. Five microtubules were mounted over each ceramic disc to restrict the bonding area $(n=20$ for each 
subgroup) (fig. 1). For multilink automix (Ivoclar ;Vivadent), a mixing tip was used to mix the base and catalyst for bis -GMA based, automixed dual cured adhesive resin cement according to manufacturer's instructions and packed into the microtubules lumen and a plastic matrix strip was placed over the resin cement and gently pressed flat and light-cured for 40 seconds using light curing unit. Following the manufacturer's recommendations, Rely X Unicem 2 (3M ESPE; Germany) was mixed using a mixing tip to blend the base and catalyst for phosphate monomer based, self-adhesive, vauto-mixed dual cured resin cement and packed into the cylinder lumen and a plastic matrix strip was placed over the resin cement and gently pressed ,then light-cured for 40 seconds using light curing unit. Specimens were kept for 24 hours at $37^{\circ} \mathrm{C}$ before starting the testing procedures.

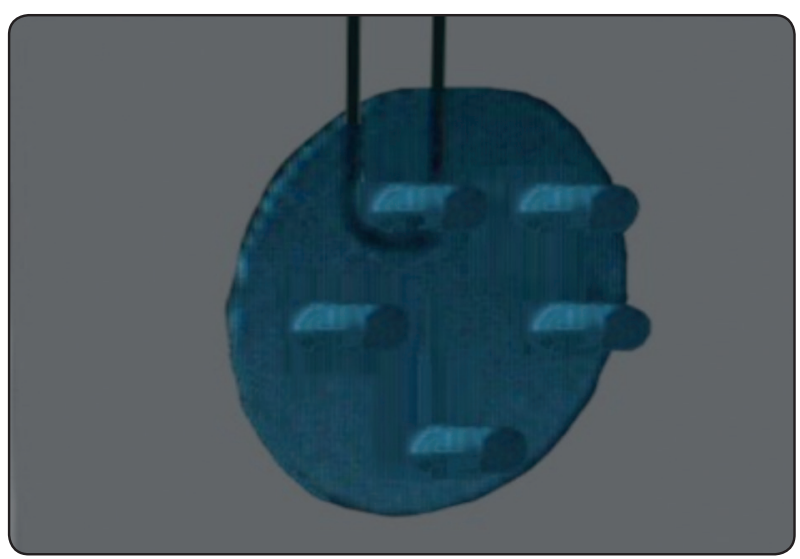

Fig. (1) Diagram of micro shear bond testing.

\section{Micro shear bond testing ( $\mu \mathrm{SBS})$}

Micro-shear bond strengths ( $\mu$ SBS) were assessed using a universal testing machine (Instron, \#3345; Norwood; USA). A $0.014 \mathrm{~mm}$ diameter wire was looped around the bonded micro-cylinder assembly as close as possible to the base of the micro-cylinder and aligned with the loading axis of the upper movable compartment of the testing machine (Fig.1). A shearing load was applied at a crosshead speed of $0.5 \mathrm{~mm} / \mathrm{min}$. until failure occurred. The load required to cause debonding was recorded in newton using computer software (Instron Software). Micro-Shear bond strength was calculated according to the formula $\mathrm{T}=\mathrm{P} / \pi \mathrm{r} 2$ where; $\mathrm{T}=$ bond strength (MPa), $\mathrm{P}=$ load at failure $(\mathrm{N})$ and $\mathrm{r}=$ radius of micro- cylinder $(\mathrm{mm})$. Data for both surface roughness (Ra) and micro-shear bond strength ( $\mu$ SBS) were assembled, organized, presented in tables and statistically analyzed.

\section{Scanning electron microscopic evaluation}

To determine the mode of failure after microshear bond strength test, one sample from each group (press, repress) and each subgroup (Multilink, Rely-X unicem2)for both tested materials was coated with gold (Ladd sputter Coater, USA) and examined by scanning electron microscope (SEMQuanta 250- FEG) at X1000 to observe the mode of failure at de-bonded ceramic-cement interfaces.

\section{Statistical Analysis}

Data were presented as mean and standard deviation (SD) values. Repeated measures Analysis of Variance (ANOVA) was used to study the effect of material or cement, condition and their interaction on mean $\mathrm{Ra}$ and micro-shear bond strength. Statistical significance level was established on $\mathrm{P} \leq 0.05$. Statistical analysis was performed with IBM SPSS Statistics for Windows, Version 23.0. Armonk, NY: IBM Corp.

\section{RESULTS}

\section{Surface roughness}

Repeated measures ANOVA results showed that the material regardless of the condition (Press and Repress) had a statistically significant effect on mean Ra. Condition regardless of material had no statistically significant effect on mean Ra. The interaction between the two variables had no statistically significant effect on mean $\mathrm{Ra}$ indicating that the variables are independent from each other Table (3), Fig.(2). 
Regardless of the condition; IPS e.max showed statistically significantly higher mean Ra than Celtra press $(P$-value $<0.001$, Effect size $=0.859)$ and $(P$-value $<0.001$, Effect size $=0.841)$, respectively. Whereas for both IPS e.max and Celtra press; there was no statistically significant difference between mean $\mathrm{Ra}$ value for press and repress conditions $(P$-value $=0.147$, Effect size $=0.244)$ and $(P$-value $=0.270$, Effect size $=0.149)$, respectively Table (4), Fig. $(2,3)$.

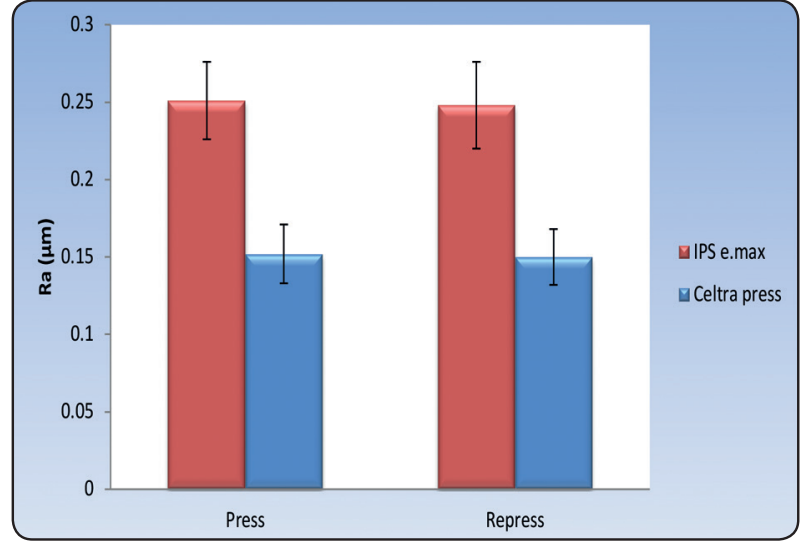

Fig. (2) Bar chart representing mean and standard deviation values for Ra of different variables.

TABLE (3) Repeated measures ANOVA results for the effect of different variables on the mean Ra values.

\begin{tabular}{|c|c|c|c|c|c|c|}
\hline Source of variation & $\begin{array}{c}\text { Type III Sum } \\
\text { of Squares }\end{array}$ & Df & Mean Square & F-value & $P$-value & $\begin{array}{c}\text { Effect size (Partial eta } \\
\text { squared })\end{array}$ \\
\hline Material & 0.049 & 1 & 0.049 & 45.922 & $<0.001 *$ & 0.852 \\
\hline Condition & 0.0005 & 1 & 0.0005 & 3.896 & 0.084 & 0.328 \\
\hline Material x Condition interaction & 0.0001 & 1 & 0.0001 & 0.089 & 0.773 & 0.011 \\
\hline
\end{tabular}

$d f:$ degrees of freedom $=(n-1)$, *: Significant at $P \leq 0.05$

TABLE (4) The mean, standard deviation (SD) values and results of repeated measures ANOVA test for comparison between Ra values with different interactions of variables.

\begin{tabular}{|c|c|c|c|c|c|c|}
\hline \multirow{2}{*}{ Condition } & \multicolumn{2}{|c|}{ IPS e.max } & \multicolumn{2}{c|}{ Celtra press } & \multirow{2}{*}{ P-value } & $\begin{array}{c}\text { Effect size (Partial } \\
\text { eta squared) }\end{array}$ \\
\cline { 2 - 6 } & Mean & SD & Mean & SD & & 0.859 \\
\hline Press & 0.251 & 0.025 & 0.152 & 0.019 & $<0.001 *$ & 0.841 \\
\hline Repress & 0.248 & 0.028 & 0.15 & 0.018 & $<0.001 *$ & \\
\hline P-value & \multicolumn{2}{|c|}{0.147} & 0.270 & & \\
\hline
\end{tabular}

\footnotetext{
*: Significant at $P \leq 0.05$
} 


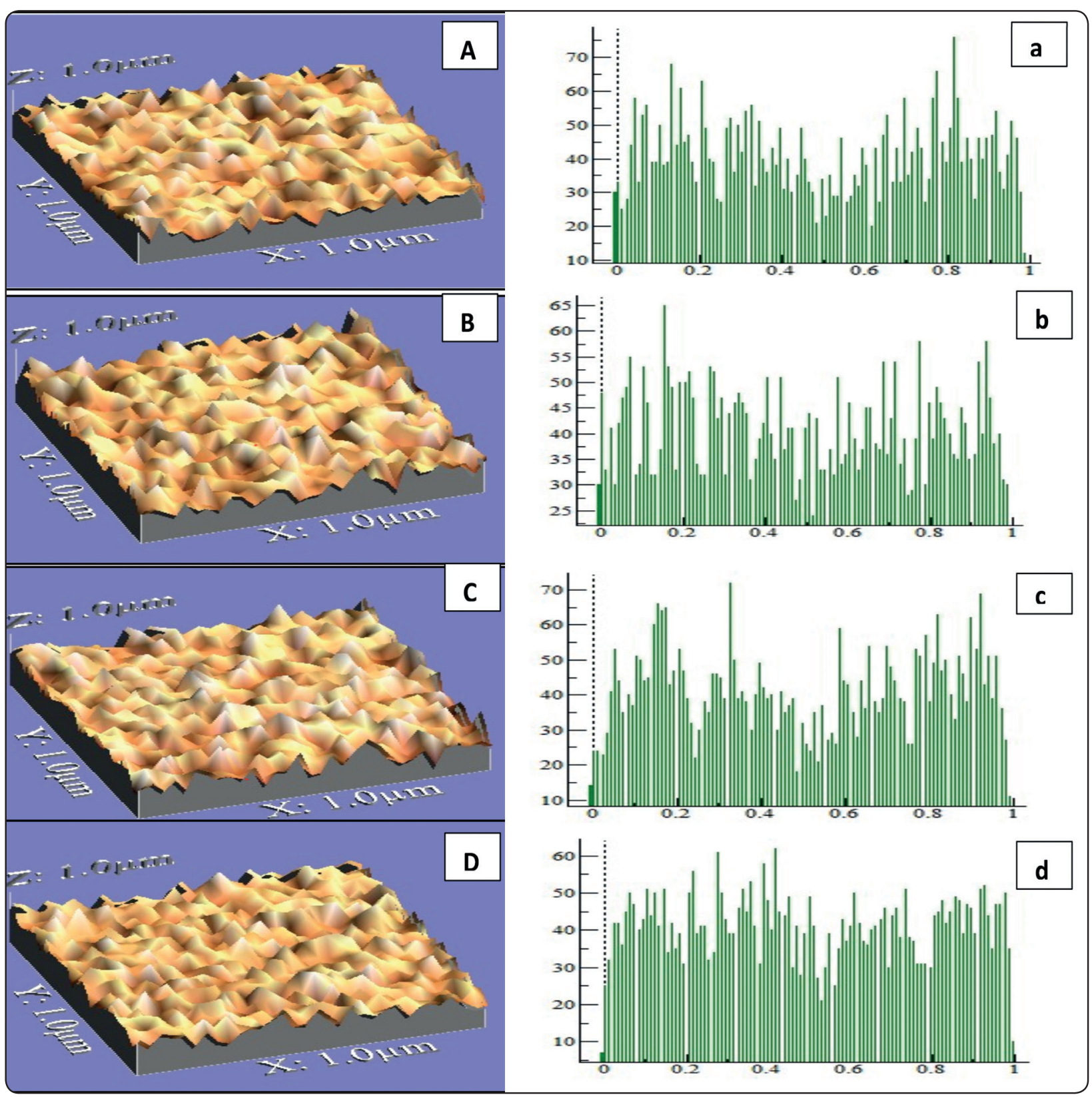

Fig. (3) Surface roughness photomicrograph and histogram ; (A ,a) IPS e.max glass ceramic material press group, (B ,b) )IPS e.max glass ceramic material repress group, $(\mathrm{C}, \mathrm{c})$ Celtra press glass ceramic material press group, $(\mathrm{D}, \mathrm{d}))$ Celtra press glass ceramic material repress group

\section{Micro-shear bond strength}

Repeated measures ANOVA results showed that pressable glass ceramics regardless of cement type and condition (press, repress) had a statistically significant effect on mean micro-shear bond strength. Cement type regardless of ceramic material and condition (press, repress) had no statistically significant effect on mean micro-shear bond strength. Condition regardless of ceramic material and cement type had a statistically significant effect on mean micro-shear bond strength. The interaction between the three variables had no statistically significant effect on mean micro-shear bond strength indicating that the variables are independent from each other Table (5). 
In spite of cement type and condition; IPS e.max showed statistically significantly higher mean micro-shear bond strength than Celtra press. Regardless of ceramic material and condition (press, repress); there was no statistically significant difference between mean micro-shear bond strength of the two cements. Apart from ceramic material and cement type; press group showed statistically significant higher mean micro-shear bond strength than repress group.

Effect of different interactions on micro-shear bond strength revealed that using IPS e.max whether with Multilink or Rely-X Unicem 2 ; press group showed a statistically significant higher mean micro-shear bond strength than repress group $(P$-value $<0.001$, Effect size $=0.583)$ and $(P$-value $=0.002$, Effect size $=0.465)$. For Celtra press; with Multilink or Rely-X Unicem 2; press group showed a statistically significant higher mean micro-shear bond strength than repress group $(P$-value $=0.002$, Effect size $=0.458)$ and $(P$-value $=0.014$, Effect size $=0.321)$ Table (6), Fig. (4).

TABLE (5) Repeated measures ANOVA results for the effect of different variables on mean micro-shear bond strength.

\begin{tabular}{|l|l|l|l|l|c|c|}
\hline Source of variation & $\begin{array}{l}\text { Type III Sum } \\
\text { of Squares }\end{array}$ & df & Mean Square & F-value & $P$-value & $\begin{array}{c}\text { Effect size }(\text { Partial } \\
\text { eta squared })\end{array}$ \\
\hline Ceramic & 120.062 & 1 & 120.062 & 5.314 & $0.035^{*}$ & 0.249 \\
\hline Cement & 92.720 & 1 & 92.720 & 4.104 & 0.060 & 0.204 \\
\hline Condition & 289.982 & 1 & 289.982 & 55.417 & $<0.001^{*}$ & 0.776 \\
\hline Ceramic x Cement x Condition interaction & 0.006 & 1 & 0.006 & 0.001 & 0.973 & 0.000 \\
\hline
\end{tabular}

$d f:$ degrees of freedom $=(n-1), *$ : Significant at $P \leq 0.05$.

TABLE (6) The mean, standard deviation (SD) values and results of repeated measures ANOVA test for comparison between micro-shear bond strength values with different interactions of variables.

\begin{tabular}{|c|c|c|c|c|c|c|c|}
\hline \multirow{2}{*}{ Ceramic } & \multirow{2}{*}{ Condition } & \multicolumn{2}{|c|}{ IPS e.max } & \multicolumn{2}{|c|}{ Celtra press } & \multirow{2}{*}{$\begin{array}{l}P \text {-value } \\
\text { (Effect of } \\
\text { ceramic) }\end{array}$} & \multirow{2}{*}{$\begin{array}{c}\text { Effect size } \\
\text { (Partial etc } \\
\text { squared) }\end{array}$} \\
\hline & & Mean & $\mathrm{SD}$ & Mean & SD & & \\
\hline \multirow{4}{*}{ Multilink automix } & Press & 24.5 & 2.9 & 21.8 & 2.9 & 0.261 & 0.078 \\
\hline & Repress & 17.7 & 3.7 & 16.5 & 2.8 & 0.638 & 0.014 \\
\hline & $P$-value (Effect of condition) & \multicolumn{2}{|c|}{$<0.001 *$} & \multicolumn{2}{|c|}{$0.002 *$} & & \\
\hline & Effect size (Partial eta squared) & \multicolumn{2}{|c|}{0.583} & \multicolumn{2}{|c|}{0.458} & & \\
\hline \multirow{4}{*}{$\begin{array}{c}\text { Rely-X Unicem2 } \\
\text { automix }\end{array}$} & Press & 22.3 & 4.7 & 16.6 & 3.8 & $0.024 *$ & 0.279 \\
\hline & Repress & 16.9 & 5.5 & 12.6 & 2.4 & 0.094 & 0.165 \\
\hline & $P$-value (Effect of condition) & \multicolumn{2}{|c|}{$0.002 *$} & \multicolumn{2}{|c|}{$0.014^{*}$} & & \\
\hline & Effect size (Partial eta squared) & \multicolumn{2}{|c|}{0.465} & \multicolumn{2}{|c|}{0.321} & & \\
\hline \multirow{2}{*}{$\begin{array}{l}P \text {-value (Effect of } \\
\text { cement) }\end{array}$} & Press & \multicolumn{2}{|c|}{0.349} & \multicolumn{2}{|c|}{0.051} & & \\
\hline & Repress & \multicolumn{2}{|c|}{0.751} & \multicolumn{2}{|c|}{0.124} & & \\
\hline \multirow{2}{*}{$\begin{array}{l}\text { Effect size (Partial } \\
\text { eta squared) }\end{array}$} & Press & \multicolumn{2}{|c|}{0.055} & \multicolumn{2}{|c|}{0.226} & & \\
\hline & Repress & \multicolumn{2}{|c|}{0.006} & \multicolumn{2}{|c|}{0.141} & & \\
\hline
\end{tabular}

\section{$*$ : Significant at $\boldsymbol{P} \leq \mathbf{0 . 0 5}$.}




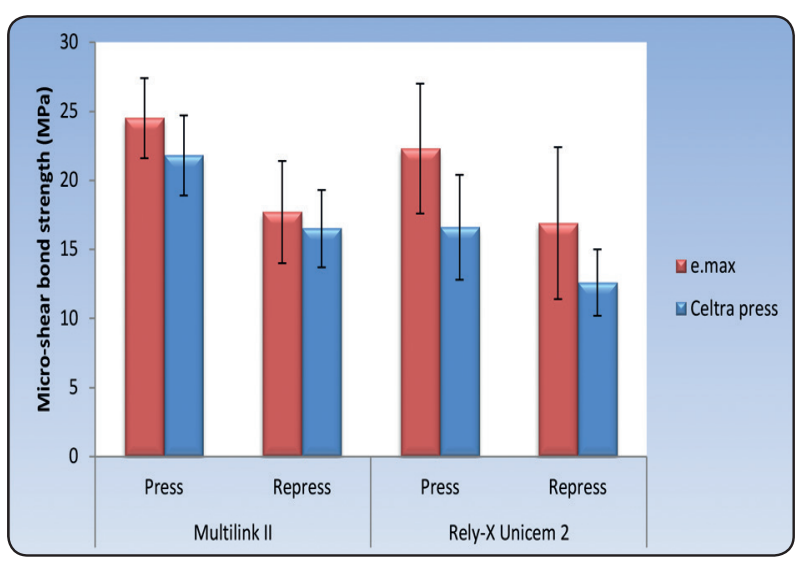

Fig. (4) Bar chart representing mean and standard deviation values for micro-shear bond strength of different variables.

\section{Scanning electron microscope examination}

SEM photos demonstrating the resin/ceramic interface for the debonded specimens of the tested groups (Fig.5). For IPS e.max (press group) with both type of cements the mode of failure was a mixed mode of failure predominated with cohesive failure within the resin cement, While for the repress group , the mode of failure was mixed mode of failure predominated with adhesive failure with areas of scattered resin cement. Whereas for Celtra press with multilink resin cement (press group) the mode of failure was mixed mode; mainly cohesive with an area of resin cement appearing stuck to the

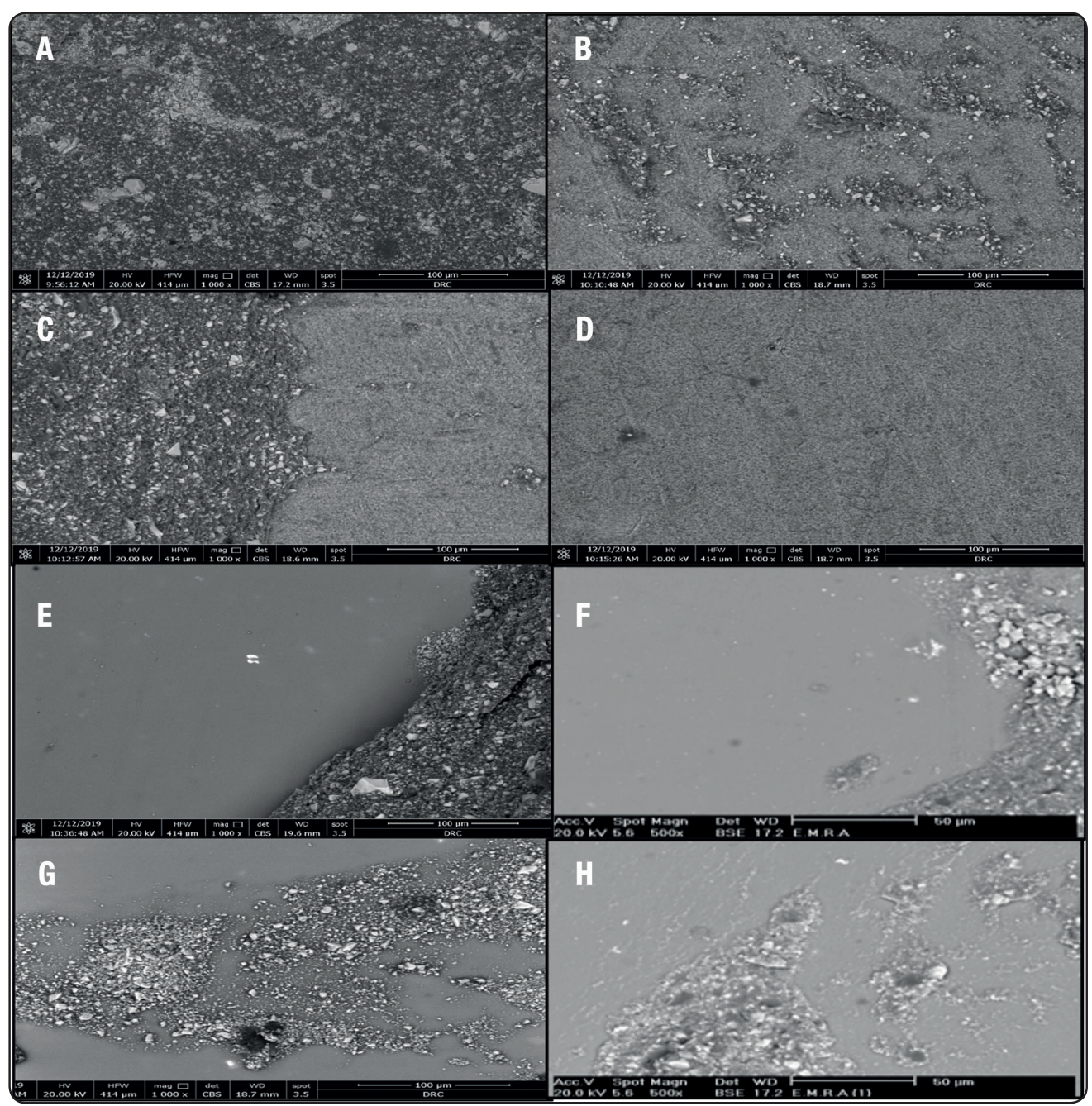

Fig. (5) SEM images of ceramic/resin interface for (A) IPS e. max press (Press group) with multilink resin cement, (B) IPS e. max press (Repress group) with multilink resin cement, (C)IPS e. max press (Press group) with Rely x unicem2 resin cement,(D) IPS e. max press (Repress group) with Rely x unicem2 resin cement, (E) Celtra press (Press group) with multilink resin cement, (F) Celtra press (Repress group) with multilink resin cement, (G)Celtra press (Press group) with Rely x unicem2 resin cement,(H) Celtra press (Repress group) with Rely x unicem2 resin cement. 
surface, although the press group (Celtra press) with rely $\mathrm{x}$ unicem 2 and repress group (Celtra press) with both type of cements, the mode of failure was mixed mode of failure predominated with adhesive failure.

\section{DISCUSSION}

The aim of this in-vitro study was to evaluate the effect of repressing on surface topography and micro-shear bond strength of Lithium di-silicate (IPS e.max press) and zirconia reinforced lithium di-silicate (Celtra press). Based on the results of this study, the null hypotheses which stated that IPS e.max press and Celtra press repressing has no adverse effect on (1) Surface topography (2) Micro-shear bond strength were partially rejected as surface roughness values have no statistically significant difference between press and repress groups for both tested materials, whereas the microshear bond strength results revealed a statistically significant difference between the press and repress samples for both tested materials regardless the type of cement used.

Surface roughness referred to very fine irregularities of the surface resulted from the process of manufacturing as well as the material itself and measured in $\mu \mathrm{m} .{ }^{28}$ The results of surface roughness test in our investigation showed that the material itself in terms of microstructure and chemical composition could be the reason for the significant difference between the two materials. IPS e.max showed statistically significant higher mean Ra than Celtra press (P-value $<0.001$, Effect size $=0.859)$ and $(\mathrm{P}$-value $<0.001$, Effect size $=$ 0.841 ), respectively. Surface roughness of the two pressable ceramics is not significantly affected by ceramic repressing (Fig. 3, 4).Explanation of these results may be credited to ingot delivery form, vacuum pressure used for ingot pressing, density as well as homogeneity in terms of pores and bond between the crystalline phase and glassy matrix, thus decreasing the chance for any defect formation inside each ingot.This was in agreement with Chung et al, ${ }^{29}$ who reported that no changes occurs in the microstructure or surface texture after repressing. Moreover, Albakry et al, ${ }^{30}$ stated that both size and number of pores was found to decrease after pressing and repressing process with improved homogenous distribution of crystals inside the glassy matrix. This might explain the insignificant difference between press and repress groups regardless of the type of material tested. Fernanda et al, ${ }^{31}$ stated that repressing of leucite based ceramic ingots enhances surface roughness and wettability. In this study, IPS e.max press showed a statistically significant higher mean Ra values $(\mu \mathrm{m})$ than Celtra press this may be attributed to the dissolving of zirconium oxide into the glassy matrix after repressing which result in more smoother surface ${ }^{32}$

Many obstacles in bond strength testing and its interpretation are well recognized by many authors. ${ }^{33,34}$ The decreased specimen size results in reduced probability of any micro-cracking to occur, the circular bonding area restriction may have provoked better stress distribution around the adhesive interface and avoided the fracture from occurring beyond the limits of the micro-cylinder. Besides, as the experimental setup did not require any specimen cutting or trimming, pretesting failures were avoided. All of these qualities favor the utilization of the micro-shear bond strength approach. ${ }^{34}$

Micro-shear bond strength results revealed that press group showed statistically higher mean micro-shear bond strength than repress samples, while there was no significant difference between micro-shear bond strength of the two adhesive resin cements used. This might be attributed to the effect of repressing on the microstructure in terms of; crystal phases in proportion to the glassy matrix, the effect of repressing on crystal length and width (size),viscosity of the remaining glass phase during heat treatment as well as decreased size and number of pores appears inside the material after repressing. ${ }^{32}$ To improve adhesion with lithium disilicate based glass ceramic restoration to adhesive resin cement, HF etching and silanization was done 
as surface treatment protocol for all disc samples, ${ }^{35}$ nevertheless different monomer composition, alterations in chemical composition, viscosity, wettability and mechanical properties of each resin cement might be blamable for the differences in the bonding strengths.$^{36}$ In accordance with our results, Fasbinder et al, ${ }^{16}$ accomplished an in-vivo study on 62 chair-side posterior crowns constructed and cemented using a bis-GMA-based, auto-mixed, dual-cure resin cement multilink II automix used with a self-etch adhesive or an experimental selfadhesive resin cement developed by the same manufacturer. They reported that only two of the 39 crowns cemented with the self-adhesive resin cement de-bonded after two years. The authors reported that the cement was retained on the crown but not on the tooth surface.

The bond strength results were coupled with assessment of mode of failure after micro-shear bond strength test. One sample from each group (press, repress) with the two cements used in this study (Multilink , Rely-X unicem2) was examined by the aid of scanning electron microscope. Regardless of the cement type; cohesive failure was observed in press group for both tested materials. In contrast with the repress group for both materials, the incidence of adhesive failure was more common, these findings support the hypothesis that the press samples gives a more reliable and superior microshear bond strength results than the repress group. Further investigations are required to investigate the effect of accelerated aging on the microshear bond strength and to study the microstructural changes that occurs after repressing of glass ceramics to clarify and support our results.

\section{CONCLUSIONS}

Within the limitations of this in vitro study, the following conclusions were established:

1. Pressing of glass ceramic materials for one injection is highly recommended.
2. Repressing of glass ceramics improved surface topography but compromises the bond strength.

3. Both tested glass ceramic materials can be recycled without significantly altering the surface roughness.

\section{REFERENCES}

1. Morimoto S, Albanesi RB, Sesma N, Agra CM, Braga MM. Main clinical outcomes of feldspathic porcelain and glass-ceramic laminate veneers: a systematic review and meta-analysis of survival and complication rates.Int $\mathbf{J}$ Prosthodont 2016;29:38-49.

2. Ansong R, Flinn B, Chung KH, Mancl L, Ishibe M, Raigrodski AJ. Fracture toughness of heat-pressed and layered ceramics. J Prosthet Dent 2013; 109:234-240.

3. Christgau M, Friedl KH, Schmalz G, Resch U. Marginal adaptation of heat-pressed glass-ceramic veneers to dentin in vitro. Oper Dent 1999; 24: 137-146.

4. Guess PC, Vagopoulou T, Zhang Y, Wolkewitz M, Strube JR. Marginal and internal fit of heat pressed versus CAD/ CAM fabricated all-ceramic onlays after exposure to thermo-mechanical fatigue. J Dent 2014; 42: 199-209.

5. Conrad HJ, Seong W-J, Pesun IJ. Current ceramic materials and systems with clinical recommendations: a systematic review. J Prosthet Dent 2007; 98:389-404.

6. Attia A, Kern M. Influence of cyclic loading and luting agents on the fracture load of two all-ceramic crown systems. J Prosthet Dent 2004; 92:551-66.

7. Manso AP, Silva NR, Bonfante EA, Pegoraro TA, Dias RA, Carvalho RM. Cements and adhesives for all-ceramic restorations.Dent Clin North Am 2011;55:311-32.

8. Guarda GB, Correr AB, Goncalves LS, Costa AR, Borges GA, Sinhoreti MA, Effects of surface treatments, thermocycling, and cyclic loading on the bond strength of a resin cement bonded to a lithium disilicate glass ceramic. Oper Dent 2013; 38:208-17.

9. Pisani-Proenca J, Erhardt MC, Valandro LF, GutierrezAceves G, Bolanos-Carmona MV, Del Castillo-Salmeron $\mathrm{R}$, Influence of ceramic surface conditioning and resin cements on microtensile bond strength to a glass ceramic. J Prosthet Dent 2006; 96:412-7.

10. Lise DP, Perdigao J, Van Ende A, Lopes GC. Microshear Bond Strength of Resin Cements to Lithium Disilicate Substrates as a Function of Surface Preparation Oper Dent, 2015, 40: 524-532.

11. Lung CYK, Matinlinna JP. Aspects of silane coupling agents and surface conditioning in dentistry: an overview. Dent Mater 2012; 28:467-77. 
12. Ozcan M, Volpato CAM. Surface conditioning protocol for the adhesion of resin-based materials to glassy matrix ceramics: how to condition and why? J Adhes Dent 2015; $17: 292-3$.

13. Ferracane JL, Stansbury JW, \& Burke FJ Self-adhesive resin cements-Chemistry, properties and clin-ical considerations J of Oral Rehab 2011, 38(4):295-314.

14. Christensen GJ .How to prepare zirconia and IPS e.max restorations for cementation Clinicians Report 2014, $6(4): 1-4$.

15. Tian T, Tsoi JK, Matinlinna JP, \& Burrow MF.Aspects of bonding between resin luting cements and glass ceramic materials Dent Mater 2014, 30(7):147-162.

16. Fasbinder DJ, Dennison JB, Heys D, Neiva G. A clinical evaluation of chairside lithium disilicate CAD/CAM crowns: A two-year report. J of Amer Dent Assoco. 2010, 141(2); 10-14.

17. Kilinc H, Turgut S. Optical behaviors of esthetic CADCAM restorations after different surface finishing and polishing procedures and UV aging: An in vitro study. J Prosthet Dent 2018; 120:107-113.

18. Ozarslan MM, Buyukkaplan US, Barutcigil C, Arslan M, Turker N, Barutcigil K . Effects of different surface finishing procedures on the changein surface roughness and color of a polymer infiltrated ceramic network material. J Adv Prosthodont 2016; 8:16-20.

19. Fathy SM, Swain MV. In-vitro wear of natural tooth surface opposed with zirconia reinforced lithium silicate glass ceramic after accelerated ageing. Dent Mater 2018; 34:551-559.

20. Bollen CML, Papaioannou W, Van Eldere J, Schepers E, Quirynen M, Van SteenbergheD. The influence of abutment surface roughness on plaque accumulation and periimplant mucositis. Clin Oral Imp Res 1996; 7:201-211.

21. Gorman CM, Horgan K, Dollard RP, Stanton KT. Effects of repeated processing on the strength and microstructure of a heat-pressed dental ceramic. J Prosthet Dent 2014; 112:1370-1376.

22. Della Bona A, Anusavice KJ. Microstructure, composition, and etching topography of dental ceramics. Int J Prosthodont 2002; 15:159-167.

23. Della-Bona A. Characterizing ceramics and the interfacial adhesion to resin: II- the relationship of surface treatment, bond strength, interfacial toughness and fractography. J Appl Oral Sci 2005; 13:101-109.
24. Sattabanasuk V, Charnchairerk P, Punsukumtana L, Burrow M. Effects of mechanical and chemical surface treatments on the resin-glass ceramic adhesion properties. J Investig Clin Dent 2017; 8; 3-10.

25. Yavuz T, Eraslan O. The effect of silane applied to glass ceramics on surface structure and bonding strength at different temperatures. J Adv Prosthodont 2016; 8:75-84.

26. Tang X, Tang C, Su H, Luo H, Nakamura T, Yatani H. The effects of repeated heat-pressing on the mechanical properties and microstructure of IPS e.max Press J Mech Behav Biomed Mater 2014; 40:390-396.

27. Kakaboura A, Fragouli M, Rahiotis C, et al. Evaluation of surface characteristics of dental composites using profilometry, scanning electron, atomic force microscopy and gloss-meter. J Mater Sci Mater Med 2007; 18: 155-63.

28. Paravina RD, Powers JM, "Esthetic colour training in dentistry", St. Louis; Mosby; 2004, 43-44.

29. Chung KH, Liao JH, Duh JG, Chan C.The effects of repeated heat-pressing on properties of pressable glass-ceramics. J Oral Rehabil.2009; 36:132-41.

30. Albakry M, Guzzato M, Swain MV. Influence of hot pressing on the microstructure and fracture toughness of two pressable dental glass-ceramics. J Biomed Mater Res Appl Biomater. 2004, 15; 71 (1): 99-107.

31. Fernanda OA, Amanda MD, Marco AB, Luiz FV, Renata MM. The Influence of Ceramic Re-pressing on Surface Properties, Bond Strength, and Color Stability of Leucite Ceramic.2018, 20(5):389-395.

32. Lubica H, Peter U, Mark DG, JustinJ, Michaël M, Frank L, Matthias K. Properties of hot-pressed lithium silicate glass-ceramics. Dent Mater 2019, 35:713-729.

33. Scherrer S, Cesar PF, Swain MV. Direct comparison of the bond strength results of the different test methods: A critical literature review. Den Mater 2010, 26(2):78-93.

34. Phrukkanon S, Burrow MF, Tyas MJ .The influence of cross-sectional shape and surface area on the microtensile bond test Dent Mater .1998, 14(3) 212-221.

35. Camila S, Manthan P,Eric D.In vitro shear bond strength of three Self-adhesive resin cements and a resin-modified glass ionomer cement to various prosthodontics substrates. Oper Dent 2013, 38(2):186-196.

36. Chang 1, Hong L, Yue TQ, Song Z, Su QZ.The influence of four dual cure resin cements and surface treatment selection to bond strength of fiber post. Int $\mathbf{J}$ of Oral Scien 2013,6::56-60. 